\title{
Alkamides from Piper longum and Piper nigrum as Inhibitors of IL-6 action
}

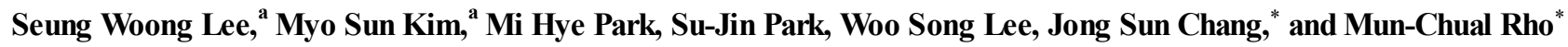 \\ Eco-friendly Biomaterial Research Center, Korea Research Institute of Bioscience and Biotechnology, Jeongeup, \\ Jeonbuk580-185, Korea.*E-mail:rho-m@kribb.re.kr(MCR),changjs@kribb.re.kr(JSC) \\ Received December 30, 2010, Accepted February 12, 2010
}

\begin{abstract}
Blocking of IL-6 has been postulated to be an effective therapy in the pathogenesis of several inflammatory diseases. The current study was performed to examine the potential effects of alkamides isolated from $P$. longum and $P$. nigrum on IL-6 induced Stat 3 activation and identify the structure-activity relationship of these alkamides in human hepatoma cells. Among 10 alkamides isolated from $P$. longum and $P$. nigrum, compounds 6,7 and $\mathbf{9}$ were identified as strong inhibitors of IL-6 action, which inhibit IL-6 induced Stat3-dependent luciferase activities. These inhibitory activities were positively influenced by the presence of piperidine moiety.
\end{abstract}

Key Words: Piper longum, Piper nigrum, Interleukin-6, Stat3

\section{Introduction}

Interleukin-6 (IL-6) is a pleiotropic-circulating cytokine and exerts multiple effects on different systems, which are associated with immune responses. ${ }^{1}$ Several studies have demonstrated that elevated IL-6 levels are associated with various inflammatory human diseases as well as cancers. Excess IL-6 production is present in rheumatoid arthritis and Crohn disease. ${ }^{2-5}$ Large quantities of IL- 6 are found in human atherosclerotic plaques and IL-6 impairs endothelium-dependent dilatation in human veins in vivo. ${ }^{6}$ Accordingly, effective antagonism of IL-6 could be therapeutically beneficial in respect to attenuating and protecting inflammatory human diseases.

The IL-6 receptor system consists of two components: a ligand-binding $80 \mathrm{kDa}$ glycoprotein chain (IL-6R) and a signal transducing glycoprotein 130 (gp130). ${ }^{7}$ IL-6 induces gp130 homodimerization after binding to its receptor, which leads to activation of the Janus kinase (Jak)/signal transducer and activator of transcription (Stat) signal transduction pathway. ${ }^{8,9}$ Especially, Activation of Stat 3 is essential for the pro-inflammatory signals mediated by IL- $6 .{ }^{10-12}$ Therefore, inhibition of IL-6-activated Stat 3 could be a good tool to screen effective therapeutic materials.

Piper longum (P. longum) and Piper nigrum (P. nigrum) are known as oriental medicinal plants and their fruits have been used for the treatment of cholera, dyspepsia, various gastric ailments, and arthritic disorders. ${ }^{13}$ Particularly, various biological activities of an alkamide from these plants, including insecticidal, anti-bacterial, and anti-inflammatory properties, have been reported. ${ }^{14-17}$ Based on these reports, we could suspect that $P$. longum and P. nigrum may be biological response modifiers associated with various human diseases. In the previous reports, we showed that the alkamides isolated from $P$. longum and $P$. nigrum inhibited acyl-CoA:cholesterol acyltransferase (ACAT) and diacylglycerol acyltransferase (DGAT). ${ }^{18-20}$ We also had proven that these alkamides inhibited the direct binding between leukocyte function-associated antigen-1 (LFA-1) and its ligands, intercellular cell adhesion molecule-1 (ICAM-1), which

\footnotetext{
${ }^{\mathrm{a}}$ These authors equally contributed to this work.
}

is very important in inflammatory responses. ${ }^{21}$

In the current study, we investigated whether these alkamides have activities on IL-6 induced Stat 3 activation. We also described the structure-activity relationship (SAR) of these alkamides as candidates for IL-6 inhibitors.

\section{Experimental Section}

The dried fruits of Piper longum $(100 \mathrm{~g})$ were extracted with $\mathrm{MeOH}(1 \mathrm{~L})$ for 7 days at room temperature. The $\mathrm{MeOH}$ extract (32 g) were evaporated and suspended in distilled water and divided into two fractions with chloroform as non-aqueous phase. The $\mathrm{CHCl}_{3}$ extract (7.5 g) were chromatographed on a silica gel $(1 \mathrm{~kg})$ using step gradient of $\mathrm{CHCl}_{3}-\mathrm{MeOH}$ solvent system $(100: 0-1: 1, \mathrm{v} / \mathrm{v})$ to give 8 fractions by TLC profile. F1 $(3.86 \mathrm{~g})$ was further fractionated using silica gel column chromatography (400 g) eluting with Hexane-EtOAc (50:1 - 1:1, v/v) to give 8 sub-fractions. For further purification, F1-3 (400 mg) was successively separated by semi-preparative HPLC (YMC $\mathrm{J}$ ' sphere ODS H-80, $4 \mu \mathrm{m}$, ø $20 \times 150 \mathrm{~mm}$; UV, $210 \mathrm{~nm}$; flow rate, $4 \mathrm{~mL} / \mathrm{min})$ with $\mathrm{MeOH}-\mathrm{H}_{2} \mathrm{O}$ elution $(80: 20, \mathrm{v} / \mathrm{v})$ to yield 1 (29 mg), 5 (32 mg), 8 (8 mg) and 9 (11 mg).

The dried fruits of Piper nigrum $(5 \mathrm{~kg})$ were extracted with $\mathrm{MeOH}(10 \mathrm{~L})$ at room temperature. The $\mathrm{MeOH}$ extract was evaporated in vacuo, yielding a residue $(500 \mathrm{~g})$. The residue was suspended in $\mathrm{H}_{2} \mathrm{O}(1.5 \mathrm{~L})$ and extracted with $\mathrm{CHCl}_{3}(5 \mathrm{~L})$. The $\mathrm{CHCl}_{3}$ extract $(157.7 \mathrm{~g})$ subjected to silica gel $(600 \mathrm{~g}) \mathrm{CC}$ using a gradient of hexane-EtOAc $(50: 1-0: 100, \mathrm{v} / \mathrm{v})$ as eluant to yield 14 fractions $(\mathrm{F} 1 \sim \mathrm{F} 14)$ by TLC profile. F10 $(8.2 \mathrm{~g})$ was subjected to reversed-phase $\mathrm{CC}(83 \mathrm{~g})$ eluted with $\mathrm{MeOH}-\mathrm{H}_{2} \mathrm{O}$ (50:50 - 100:0, v/v), to yield 8 subfractions (F10-1 F10-8). F10-4 (1.6 g) and F10-5 (4.3 g) were further separated via lowpressure liquid chromatography [Lichroprep RP-18 Lobar column, 40 - $63 \mu \mathrm{m}$; flow rate, 6 and $8 \mathrm{~mL} / \mathrm{min}$; UV, $210 \mathrm{~nm}$ ] with elution of $\mathrm{MeOH}-\mathrm{H}_{2} \mathrm{O}(75: 25$ and 80:20, v/v), to yield three and four subfractions (F10-4-1 F10-4-3 and F10-5-1 F10-54), respectively. F10-5-2 (85.3 mg) was subjected to semi-prep HPLC (MeOH- $\left.\mathrm{H}_{2} \mathrm{O}, 80: 20, \mathrm{v} / \mathrm{v}\right)$, yielding 2 (27 mg) and 7 (42 $\mathrm{mg}$ ). F10-4-3 (837 mg) was successively separated via semi- 
prep HPLC (YMC J' sphere ODS H-80, $4 \mu \mathrm{m}$, ø $20 \times 150 \mathrm{~mm}$; $\mathrm{UV}, 254 \mathrm{~nm}$; flow rate, $4 \mathrm{~mL} / \mathrm{min}$ ) with $\mathrm{MeOH}-\mathrm{H}_{2} \mathrm{O}$ elution $(75: 25, \mathrm{v} / \mathrm{v})$ to yield $3(11 \mathrm{mg})$. F11 $(1.2 \mathrm{~g})$ was subjected to reversed-phase $\mathrm{CC}(24 \mathrm{~g})$ with $\mathrm{MeOH}-\mathrm{H}_{2} \mathrm{O}$ elution (50:50 100:0, v/v), yielding 9 subfractions (F11-1 F11-9). Fractions F11-4,5 (1.07 g) were further separated via low-pressure liquid chromatography $\left(\mathrm{CH}_{3} \mathrm{CN}-\mathrm{H}_{2} \mathrm{O}=80: 20\right.$, v/v) to yield five subfractions (F11-4,5-1 F11-4,5-5). F11-4,5-2 and F11-4,5-3 were subjected to semi-prep HPLC $\left(\mathrm{CH}_{3} \mathrm{CN}-\mathrm{H}_{2} \mathrm{O}=70: 30\right.$, v/v) to yield 4 (60 mg) and 6 (123 mg), respectively.

Recombinant human IL-6 was purchased from R\&D systems (Minneapolis, MN, USA). Mouse anti-phospho Stat3 (Tyr ${ }^{705}$ ) IgG was purchased from Calbiochem (Darmstadt, Germany). Anti-total Stat3 IgG and secondary antibody were acquired from Cell Signaling Technology Inc. All solvents are analytical grade and obtained from Burdick \& Jackson (Muskegon, MI, USA). All reagents were obtained from Sigma-Aldrech Ltd (St Louis, MO, USA). For the searching of IL-6 inhibitors, we used a pStat3-Luc construct transfected into human hepatoma (HepG2) cells (ATCC No. CRL 7922, Rockville, MD). The construction of pStat3-Luc encoding the Stat3 binding site was purchased from Clontech laboratories (Palo Alto, CA). This luciferase reporter construct contains TA minimal promoter with four tandem Stat3-binding sites. Cells were transfected with pStat3Luc using transfection reagent lipofectamine plus (Invitrogen, Carlsbad, CA, USA) according to the manufacturer's protocol. pRL-CMV encoding renillar luciferase was also transfected. After 24 hours at incubation condition, cells were performed starvation for 24 hours, and then treated with IL-6 $(10 \mathrm{ng} / \mathrm{mL})$ with or without compounds for 12 hours. Luciferase assay was performed with kit from Promega according to the manufacturer's protocol. Firefly luciferase activity was normalized to renillar luciferase activity. We also investigated effects of active compounds on the phosphorylation of Stat 3 induced by IL-6 with western blot. Total proteins were prepared from cells and were subjected to Western blot ${ }^{22}$ with primary rabbit anti-phospho Stat3 $\left(\mathrm{Tyr}^{705}\right) \mathrm{IgG}$, anti-total Stat3 $\operatorname{IgG}(1: 1000)$. All experiments were performed three times. Data were expressed as mean \pm SE. Statistical analysis was performed using SigmaPlot Statistical Analysis software.

\section{Results and Discussion}

To investigate IL-6 inhibitors from natural sources, we used a pStat3-Luc construct transfected into human hepatoma (HepG2) cells. HepG2 cells have been previously shown to express the specific IL-6 receptor. ${ }^{23}$ The MeOH extracts of $P$. longum and $P$. nigrum were fractionated by repeated open-column chromatography on silica gel and ODS, LPLC and semi-preparative HPLC to afford nine alkamides (1-9), and they showed inhibitory effects on Stat3-dependent luciferase activities induced by IL-6. Compound 7 was isolated as colorless oil, which exhibited a UV spectrum with $\lambda_{\max }$ at 260.5 and $305 \mathrm{~nm}$. It exhibited a molecular ion peak at $\mathrm{m} / \mathrm{z} 366[\mathrm{M}+\mathrm{Na}]^{+}$in the ESI-MS and the molecular formula was determined as $\mathrm{C}_{21} \mathrm{H}_{29} \mathrm{NO}_{3}$. In the ${ }^{1} \mathrm{H}-\mathrm{NMR}$ spectrum, the signals of two olefinic protons were shown at $\delta 6.03(1 \mathrm{H}, \mathrm{dt}, J=15.9,6.9 \mathrm{~Hz}, \mathrm{H}-8)$ and $6.27(1 \mathrm{H}$, $\mathrm{d}, J=15.3 \mathrm{~Hz}, \mathrm{H}-9$ ) and the methylenedioxy group was also shown the signal of a two proton singlet peak $(\delta 5.92$, s). Moreover, the signals of six methylene protons and overlapping pro-
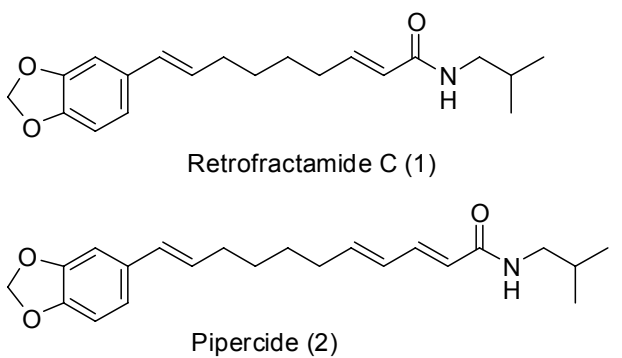<smiles>CCCCC/C=C/C=C/C(=O)NCC(C)C</smiles><smiles>CC(C)CNC(=O)CCCCCC/C=C/c1ccc2c(c1)OCO2</smiles>

Dehydroretrofractamide C (4)
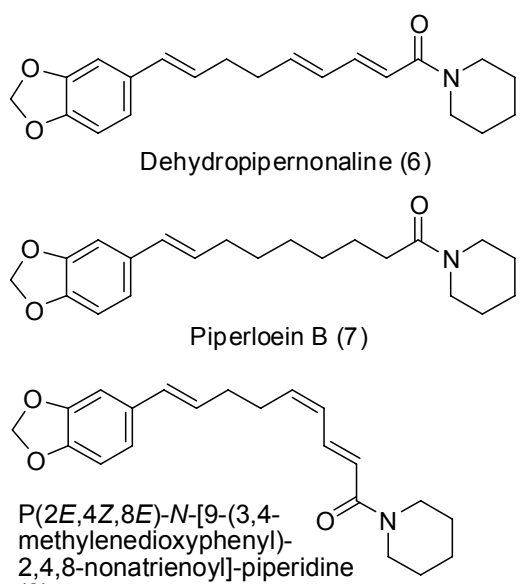

(8)

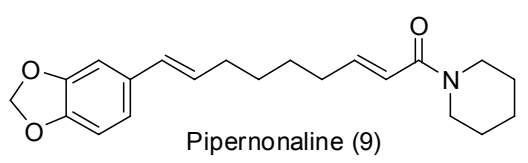

Guineesine (5)

Piperine (10)

Figure 1. The chemical structures of ten alkamides isolated from P. longum and P. nigrum. 
Table 1. Inhibitory effects of alkamides on the IL-6-induced Stat3 activation

\begin{tabular}{cc}
\hline Compounds No. & $\mathrm{IC}_{50}(\mu \mathrm{M})$ \\
\hline 1 & $>50$ \\
2 & $>50$ \\
3 & $15.38 \pm 4.46$ \\
4 & $>50$ \\
5 & $-^{a}$ \\
6 & $4.84 \pm 0.01$ \\
7 & $3.04 \pm 0.12$ \\
8 & $30.30 \pm 1.70$ \\
9 & $5.23 \pm 1.09$ \\
10 & $47.40 \pm 0.30$ \\
Genistein $^{b}$ & $14.96 \pm 0.08$ \\
\hline
\end{tabular}

Data are mean \pm standard error values of three replications. ${ }^{a}$ There is no inhibitory activity. ${ }^{b}$ Genistein was used as a positive control.
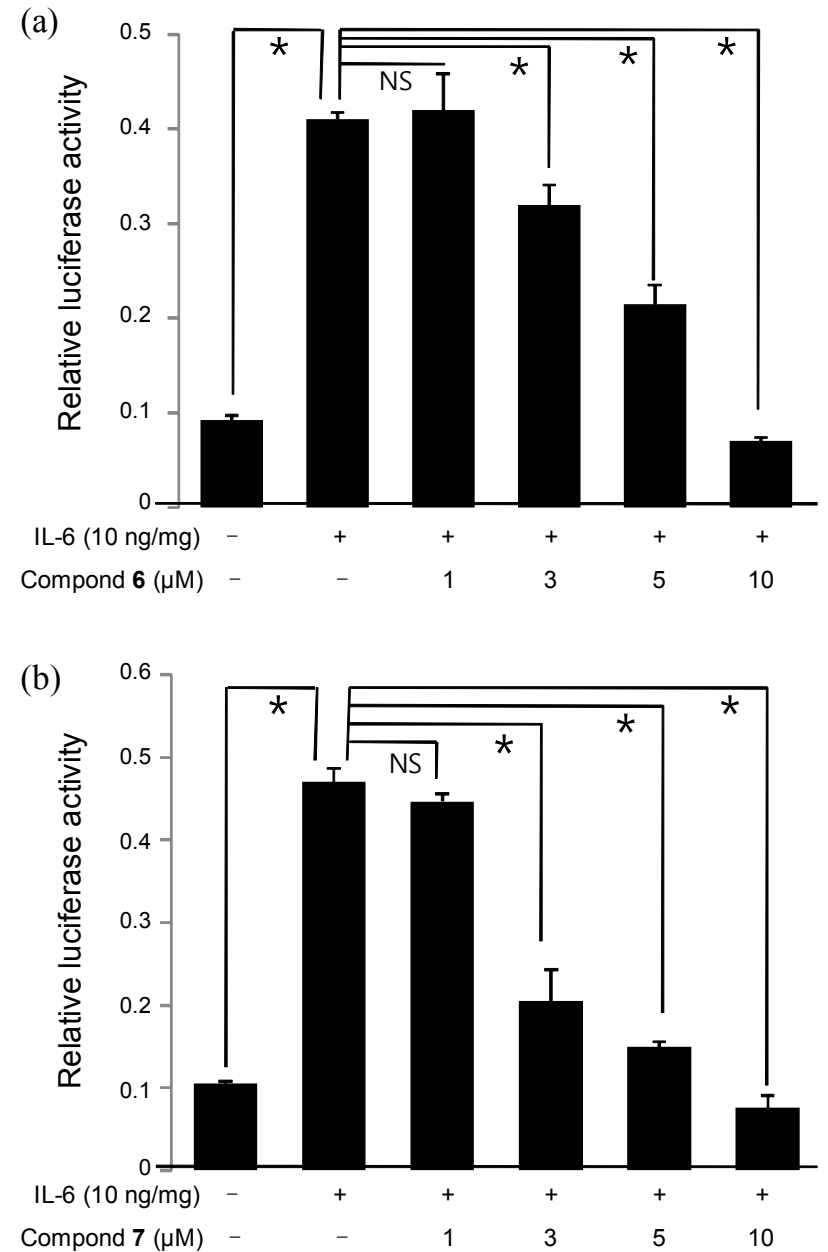

Figure 2. Inhibition of IL-6 induced Stat 3 activation by compound 6 and compound 7. HepG2 cells were transiently co-transfected with pStat3-Luc reporter and pRL-CMV-Rluc. After 24 hours serum starvation, cells were treated with IL-6 for 12 hours in the presence or absence of (a) compound $\mathbf{6}$ and (b) compound 7 as indicated concentrations. Luciferase assay was performed as described in manufacturer's protocol. Results are shown as relative luciferase activity. All experiments were repeated more than 3 times. $* \mathrm{P}<0.05$, NS $=$ Non Significant.

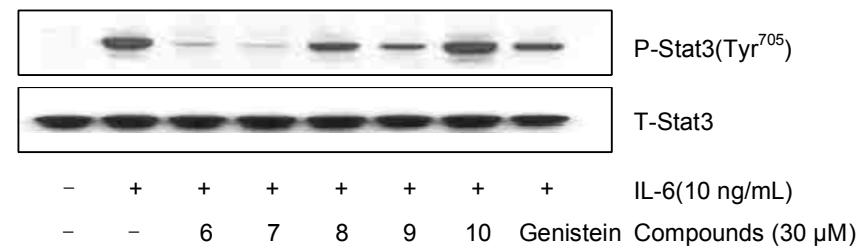

Figure 3. Inhibitory effects of alkamides on the Stat 3 phosphorylation induced by IL- 6 . HepG2 cells were incubated with IL-6 for 20 minutes in the presence or absence of alkamides $(30 \mu \mathrm{M})$, and total protein were isolated. Immunoblotting with anti-phospho Stat $3\left(\mathrm{Tyr}^{705}\right)$ and antitotal Stat3 IgG were performed on total protein (10 $\mu \mathrm{g}$ protein/lane). The experiment was performed three times.

tons of piperidine ring were observed at $\delta 2.16-2.30(4 \mathrm{H})$ and 1.35 - $1.61(14 \mathrm{H})$, respectively. Also, two broad singlet peak of piperidine ring ( $\delta 3.38$ and 3.54 , each $2 \mathrm{H}$, br s) were observed. The ${ }^{13} \mathrm{C}-\mathrm{NMR}$ spectrum showed the presence of 21 carbons: one carbonyl carbon, one methylendioxy carbon, two olefinic carbons, six methylene carbons, carbon of piperidine and benzene ring. On the basis of these data, 7 has one olefinic group adjacent benzyl group instead of carbonyl group, its structure was identified as piperrolein B by comparison with the published data. ${ }^{16}$ Also, nine known compounds were identified as retrofractamide $\mathrm{C}$ (1), pipercide (2), pellitorin (3), dehydroretrofractamide C (4), guineensine (5), dehydropipernonaline (6), $(2 E, 4 Z, 8 E)-N$ - $[9-$ (3,4-methylenedioxyphenyl)-2,4,8-nonatrienoyl] piperidine (8) and pipernonaline (9) via comparisons with previously published data. ${ }^{18-20}$ As shown in Figure 1, they can be divided into two groups: those with isobutyl (1-5) and piperidine moieties (6-10), all of which have 3,4-methylenedioxyphenyl and carbonyl groups. But compound $\mathbf{3}$ which possesses an aliphatic acyl group instead of a 3,4-methylenedioxyphenyl group. Whereas compounds $2,3,5,6,8$ and 10 have conjugated dienamide groups, compounds 1 and $\mathbf{9}$ have conjugated monoenamide groups, and compounds 4 and 7 have non-conjugated amide systems.

Ten alkamides were tested for inhibitory effects on Stat3dependent luciferase activities induced by IL-6. HepG2 cells were stimulated with IL-6 $(10 \mathrm{ng} / \mathrm{mL})$ for 12 hours in the presence or absence of compounds. This activity was verified using genistein as a positive control, which inhibited Stat3-dependent luciferase activity with an $\mathrm{IC}_{50}$ value of $15 \mu \mathrm{M}$ in this assay system. The biological data for alkamide derivatives 1-10 has been shown in Table 1 and dose-dependent effects of compound 6 and 7 which have strong inhibitory effect on IL-6 induced Stat3 activation in Figure 2. Compounds 1, 2, 4 and 5 having isobutyl amide moiety was less potent in the inhibition of IL-6induced reporter gene assay. However, compounds 6-10 substituted with piperidine amide group showed potent inhibitory activity for IL-6-induced reporter gene assay. Compound $\mathbf{3}$ also showed moderate activity. Above all, compound 7 having one trans double bond at C-9 position showed potent inhibitory activity with $\mathrm{IC}_{50}$ value of $3.04 \mu \mathrm{M}$. Whereas, the analogues 6 and 9 having two and three trans double bond moieties between 3,4-methylenedioxyphenyl and piperidine amide showed slightly less potency with $\mathrm{IC}_{50}$ value of 4.84 and $5.23 \mu \mathrm{M}$, respectively. The compound $\mathbf{8}$ involving cis and trans conjugated double bond at C-3 and C-5 showed less potent inhibitory activi- 
ty with $\mathrm{IC}_{50}$ value of $30.30 \mu \mathrm{M}$ compared with compound 6 . These results explained that the inhibitory activity may be affected by the decrease of double bond at C-3 and C- 9 position. In addition, 'trans' form of these compounds might exert some influence on IL-6-induced inhibitory activity, as compound 6 had the more potent activity than 'cis' form of compound $\mathbf{8}$. And then, compound 10 having four carbon between 3,4-methylenedioxyphenyl and piperidine amide led to decrease in 9-fold less potency compared to compound $\mathbf{9}$ having eight carbon. Also, compounds $\mathbf{2}$ having ten carbon showed slightly less potency and compound $\mathbf{5}$ having twelve carbon showed no inhibitory activity compared with compound 1 having eight carbon. It indicates that the eight carbon chain between the 3,4-methylenedioxyphenyl groups and piperidine amide can confer a potent inhibitory effect on Stat3-dependent luciferase activities induced by IL-6. Compound 3 substituted with aliphatic acyl group possessing trans conjugated bond showed moderately inhibitory activity with $\mathrm{IC}_{50}$ value of $15.38 \mu \mathrm{M}$. In brief, IL-6-induced inhibitory activities of alkamides were positively influenced by the presence of piperidine moiety. All compounds tested have no cytotoxicity in HepG2 cells with MTT assay (data not shown). Since phosphorylation of Stat 3 is necessary for its activation by IL-6, we confirmed effects of active alkamides on the phosphorylation of Stat 3 induced by IL-6. As shown in Figure 3, tyrosine phosphorylation of Stat 3 was induced by IL-6 treatment for 20 minutes, and it was inhibited by pretreatment with compound 6,7 , and 9, which are consistent result with inhibitory effect on Stat3-dependent luciferase activity. Based on these results, several alkamides from $P$. longum and $P$. nigrum could be good candidates for the therapeutic strategy of inflammatory diseases and the SAR study could be basis for the design of specific and enhanced IL-6 inhibitors.

\section{Conclusion}

In the present report, we provide the novel finding that several alkamides isolated from $P$. longum and $P$. nigrum have inhibitory effects on the Stat 3 activation induced by IL- 6 in hepatoma cells. The presence of piperidine moiety affects the inhibitory activity of these compounds on Stat3-dependent luciferase activities and on the phosphorylation of Stat 3 induced by IL-6. This report suggests that understanding the AR of alkamides from $P$. longum and $P$. nigrum on the inhibitory effect of Stat 3 activation induced by IL- 6 could be a useful therapeutic strategy in the inhibition of IL-6 inflammatory action.

Acknowledgments. This research was supported by the National Research Foundation of Korea (NRF) (No. 2009-
0081750) grant funded by the Korea government (MEST) and a KRIBB Research Initiative Program.

\section{References}

1. Strassmann, G.; Masui, Y.; Chizzonite, R.; Fong, M. J. Immunol. 1993, 150, 2341.

2. Yoshizaki, K.; Matsuda, T.; Nishimoto, N.; Kuritani, T.; Taeho, L.; Aozasa, K.; Nakahata, T.; Kawai, H.; Tagoh, H.; Komori, T.; Kishimoto, S.; Hirano, T.; Kishimoto, T. Blood 1989, 74, 1360.

3. Takagi, N.; Mihara, M.; Moriya, Y.; Nishimoto, N.; Yoshizaki, K.; Kishimoto, T.; Takeda, Y.; Ohsugi, Y. Arthritis. Rheum. 1998, 41, 2117.

4. De la Mata, J.; Uy, H. L.; Guise, T. A.; Story, B.; Boyce, B. F.; Mundy, G. R.; Roodman, G. D. J. Clin. Invest. 1995, 95, 2846.

5. Zhang, X. G.; Bataille, R.; Jourdan, M.; Saeland, S.; Banchereau, J.; Mannoni, P.; Klein, B. Blood 1990, 76, 2599.

6. Bhagat, K.; Valance, P. Circulation 1997, 96, 3042.

7. Hayashi, M.; Rho, M. C.; Enomoto, A.; Fukami, A.; Kim, Y. P.; Kikuchi, Y.; Sunazuka, T.; Hirose, T.; Komiyama, K.; Omura, S. Proc. Natl. Acad. Sci. USA 2002, 99, 14728.

8. Lütticken, C.; Wegenka, U.; Yuan, J.; Buschmann, J.; Schindler, C.; Ziemiecki, A.; Harpur, A.; Wilks, A.; Yasukawa, K.; Taga, T.; Kishimoto, T.; Barbieri, G.; Pellegrini, S.; Sendtner, M.; Heinrich, P. C.; Horn, F. Science 1994, 263, 89.

9. Ihle, J. Cell 1996, 84, 331.

10. Sebti, S.; Der, C. Nat. Rev. Cancer 2003, 3, 945.

11. Darnell, J., Jr. Science 1997, 277, 1630.

12. Aaronson, D.; Horvath, C. Science 2002, 296, 1653.

13. Jung, B. S.; Shin, M. K. Encyclopedia of Illustrated Gorean Natural Drugs; Young Lim Sa: Seoul, 1998; p 439.

14. Kiuchi, F.; Nakamura, N.; Tsuda, Y.; Kondo, K.; Yoshimura, H. Chem. Pharm. Bull. 1988, 36, 2452.

15. Mujumdar, A. M.; Dhuley, J. N.; Deshmukh, V. K.; Raman, P. H.; Naik, S. R. Jpn. J. Med. Sci. Biol. 1990, 43, 95.

16. Park, I. K.; Lee, S. G.; Shin, S. C.; Park, J. D.; Ahn, Y. J. J. Agric. Food Chem. 2002, 50, 1866.

17. Reddy, S. V.; Srinivas, P. V.; Praveen, B.; Kishore, K. H.; Raju, B. C.; Murthy, U. S.; Rao, J. M. Phytomedicine 2004, 11, 697.

18. Lee, S. W.; Rho, M. C.; Nam, J. Y.; Lim, E. H.; Kwon, O. E.; Kim, Y. H.; Lee, H. S.; Kim, Y. K. Planta Med. 2004, 70, 678.

19. Rho, M. C.; Lee, S. W.; Park, H. R.; Choi, J. H.; Kang, J. Y.; Kim, K.; Lee, H. S.; Kim, Y. K. Phytochemistry 2007, 68, 899.

20. Lee, S. W.; Rho, M. C.; Park, H. R.; Choi, J. H.; Kang, J. Y.; Lee, J. W.; Kim, K.; Lee, H. S.; Kim, Y. K. J. Agric. Food Chem. 2006, 54, 9759.

21. Lee, S. W.; Kim, Y. K.; Kim, K.; Lee, H. S.; Choi, J. H.; Lee, W. S.; Jun, C. D.; Park, J. H.; Lee, J. M.; Rho, M. C. Bioorg. Med. Chem. Lett. 2008, 18, 4544.

22. Yan, S. F.; Zou, Y. S.; Gao, Y.; Zhai, C.; Mackman, N.; Lee, S. L.; Milbrandt, J.; Pinsky, D.; Kisiel, W.; Stern, D. Proc. Natl. Acad. Sci. USA 1998, 95, 8298.

23. Tenhumberg, S.; Schuster, B.; Zhu, L.; Kovaleva, M.; Scheller, J.; Kallen, K. J.; Rose-John, S. Biochem. Biophys. Res. Commun. 2006, 346, 649. 